\title{
Heterogeneous expression and polymorphic genotype of glutathione S-transferases in human lung
}

\author{
A M Cantlay, C A D Smith, W A Wallace, P-L Yap, D Lamb, D J Harrison
}

\begin{abstract}
Background - Glutathione S-transferases (GSTs) are involved in the detoxification of xenobiotics by conjugation with glutathione. One of the mu class genes of this superfamily of enzymes, GSTM1, is polymorphic because of a partial gene deletion. This results in a failure to express GSTM1 in approximately $50 \%$ of individuals. Several studies have linked GSTM1 null status to an increased risk of lung carcinoma. This study investigated the expression and distribution of GST isoenzymes in human lung, and developed a polymerase chain reaction (PCR) assay which would allow genotyping of archival, paraffin embedded lung tissue.

Methods - Distribution was examined using a panel of polyclonal anti-GST antibodies for immunohistochemistry in normal tissue of 21 tumour-bearing lungs. DNA for PCR was extracted from paraffin blocks and a control group of 350 blood lysates. As a positive control each assay amplified part of GSTM4, a mu class gene which is not polymorphic but which shows strong sequence homology to GSTM1. The presence of GST in bronchoalveolar lavage fluid was sought by Western analysis.
\end{abstract}

Results - Proximal airways contained pi class GST, alpha class GST, and mu class GST with expression concentrated in the brush border. In distal airspaces no alpha GST was expressed but pi GST and mu GST were present in alveolar cells and also alveolar macrophages. Pi class GST was present in bronchoalveolar lavage fluid. The PCR assay enabled genotypic determination using DNA extracted from archival material. Of the control group $56 \%$ were null at the GSTM1 locus.

Conclusions - The distribution of GST isoenzymes in the lung is heterogeneous with an apparent decrease in GST in distal lung. Since GSTM1 status has already been associated with susceptibility to disease, the PCR assay developed will allow further studies of the relation between genotype and structural disorders in the lung using archival pathological material.

(Thorax 1994;49:1010-1014)

Glutathione S-transferases (GSTs) are a superfamily of enzymes involved in the conjugation of a wide range of electrophilic substrates with glutathione, thereby facilitating detoxification and further metabolism and ex- cretion. Regulation of GST expression is complex: it has tissue specificity in terms of distribution and it may be induced by xenobiotics, including carcinogens such as aromatic hydrocarbons and benzo(a)pyrene, which are present in cigarette smoke. ${ }^{1}$ At least five different families exist, four cytosolic (GST P, A, $M$, and $T$ ) and at least one microsomal GST. ${ }^{2}$ GSTP and $M$ are both involved in the detoxification of 7,8-dihydroxy-9,10-oxy-7,8,9, 10-tetrahydrobenzo(a)pyrene, an active cytochrome P450-derived metabolite of benzo(a)pyrene. ${ }^{3}$ Although GST catalytic activity is much higher in liver, lung GST is probably of importance in the primary metabolism of many inhaled xenobiotics present in cigarette smoke or the atmosphere. Furthermore, GSTs can be induced in mouse lung by phenolic antioxidants such as butylated hydroxyanisole. ${ }^{4}$ GSTM contains at least five distinct genes. ${ }^{5}$ Owing to a polymorphism of human GSTM1, which comprises a deletion of part of exons 4 and 5 of the gene, about half of the population fail to express this isoenzyme. ${ }^{6}$ Several studies have shown that individuals who fail to express GSTM1 are more susceptible to pituitary adenoma and to developing adenocarcinoma of colon and lung. ${ }^{7-12}$ This indicates that individuals with a GSTM1 nulled genotype/ phenotype have less protection against chemical stress.

In addition to xenobiotic metabolism, some human GSTs have significant seleniumindependent glutathione peroxidase activity, ${ }^{1}$ and they are also implicated in non-substrate covalent binding of some carcinogens. ${ }^{13}$ The conjugation of leukotriene A4 with glutathione to produce the cysteinyl leukotrienes $\mathrm{C} 4, \mathrm{D} 4$, and E4 is a GST-dependent reaction. ${ }^{14}$ Since leukotrienes are intimately involved in lung injury and inflammation, variation of GST expression between individuals may have significant effects on the extent of lung injury.

Several studies of GST distribution in rats ${ }^{15}$ or mice ${ }^{4}$ have been published but there are few reports on the distribution of GST isoenzymes in adult human lung. ${ }^{16-18}$ In this paper we describe the distribution of GST isoenzymes in human lung tissue and bronchoalveolar lavage fluid, and describe a polymerase chain reaction assay for determining the GSTM1 genotype using DNA derived from formalin fixed archival biopsy and autopsy material.

\section{Methods}

LUNG TISSUE

Twenty one lungs or lobes of lungs obtained 
at pneumonectomy were studied. These lungs had been removed because of small peripheral tumours which proved to be lung carcinomas. For histological preparation lungs were fixed inflated with buffered formalin for 24 hours before selection of blocks from macroscopically normal lung. All but two of the patients from whom tissue was taken were known cigarette smokers. These blocks were then processed to paraffin wax and sectioned at $2 \mu \mathrm{m}$ for immunohistochemical study.

\section{IMMUNOHISTOCHEMISTRY}

Polyclonal rabbit antisera to human GST were donated by Dr J D Hayes and have been described elsewhere. ${ }^{19}$ Anti-GSTP was raised against purified human lung GSTP and the other antisera were raised against human liver preparations. This antibody reacted only with GSTP in liver and lung Western blots, and cross reacted with no other GST isoenzyme. Anti-GSTM was raised against liver GSTM which is the product of the GSTM1 gene. However, since GSTM4 has greater than $90 \%$ sequence homology with GSTM $1,{ }^{15}$ it is possible that the polyclonal antibody could react with the product of both genes. The immunostaining protocol was as described previously ${ }^{19}$ using avidin-peroxidase and 3,3-diaminobenzidine detection. The only addition was preincubation of sections with $50 \%$ pooled normal human serum in Tris-buffered saline (TBS). This preincubation resulted in significant reduction of background staining in controls using normal rabbit serum instead of polyclonal antibody. Antisera were used at a dilution of $1: 200$ in TBS containing 5\% normal swine serum. Sections were assessed by two independent observers who then discussed the results at a twin headed microscope.

WESTERN BLOT ANALYSIS OF BRONCHOALVEOLAR LAVAGE FLUID

Four bronchoalveolar lavage fluid samples were obtained from healthy volunteers. These were not obviously blood stained. Following centrifugation to remove cellular debris, $10 \mathrm{ml}$ aliquots were taken and placed in separate lengths of $14 \mathrm{~mm}$ Viskose dialysis tubing (Medicell International Ltd, London, UK). Protein was concentrated by dialysis against glycol methacrylate (BDH Chemicals, Poole, Dorset, UK) overnight at $4^{\circ} \mathrm{C}$ to give a final sample volume of $200 \mu \mathrm{l}$. An aliquot of this concentrate was tested for the presence of haemoglobin using proprietary Dipstix to ensure that GST detected was not simply the result of leakage from red blood cells. The protein extract was mixed with an equal volume of sample buffer ( $3.6 \mathrm{ml}$ distilled water, $1 \mathrm{ml} \mathrm{0.5 \textrm {M }}$ Tris- $\mathrm{HCl} \mathrm{pH} 6.8,10 \% \mathrm{w} / \mathrm{v}$ SDS, $0.8 \mathrm{ml} 1 \mathrm{M}$ dithiothreitol, $0.8 \mathrm{ml}$ glycerol, and $0.05 \mathrm{ml}$ $0.05 \% \mathrm{w} / \mathrm{v}$ bromophenol blue) and boiled for five minutes before loading on a $7 \cdot 5 \%$ polyacrylamide gel. Purified GSTP (Sigma, UK) and liver cytosol were included as controls for antibody specificity. Protein was transferred to nitrocellulose and probed with GSTP antibody. Detection was by enhanced chemiluminescence (Amersham, UK).

\section{POLYMERASE CHAIN REACTION (PCR)}

Preparation of $D N A$

DNA was extracted from paraffin blocks, mounted tissue sections and peripheral blood using a modification of published techniques. ${ }^{2021}$ Sections were cut at $10 \mu \mathrm{m}$ from blocks or scraped from slides and placed in an Eppendorf tube. To this was added $400 \mu \mathrm{l}$ buffer $\mathrm{A}(50 \mathrm{mM} \mathrm{KCl}, 2.5 \mathrm{mM} \mathrm{MgCl}, 20 \mathrm{mM}$ Tris- $\mathrm{HCl}$ ( $\mathrm{pH} 8.0$ ), $0.45 \%$ Nonidet $\mathrm{P}-40$, $0.45 \%$ Tween-20) containing $200 \mathrm{mg} / \mathrm{ml}$ proteinase $\mathrm{K}$. The sections were then incubated for two hours at $55^{\circ} \mathrm{C}$ before boiling for 20 minutes and storing at $4^{\circ} \mathrm{C}$. In PCR reactions $15 \mu \mathrm{l}$ of this crude solution was used as template DNA. Control blood samples were collected from a randomly selected, anonymous white population $(n=350)$ at a routine blood donor clinic.

\section{PCR assay}

The PCR buffer was a standard mix of nucleotides and contained 3\% DMSO. The amplification was achieved by adding five units of Taq polymerase (Promega, UK) in a hot start, and undergoing 35 amplifications of $59^{\circ} \mathrm{C}$ for 30 seconds, $72^{\circ} \mathrm{C}$ for 90 seconds, and $94^{\circ} \mathrm{C}$ for 30 seconds. Amplified DNA was electrophoresed in 3\% agarose gels. DNA was visualised by ethidium bromide staining and examined under ultraviolet irradiation.

\section{Primers}

The primer strategy used a modification of that used by Zhong et $a l^{9}$ and Shea et $a l^{22}$ (fig 1). This method allowed the amplification of both GSTM1 and GSTM4 and hence provided a positive control for each reaction since GSTM4, which is not polymorphic, ${ }^{5}$ was always amplified. This was particularly important as DNA extracted from archival paraffin blocks may be of poor yield. A loss of GSTM1 identified in this way could therefore be distinguished from a failed PCR reaction.

The following oligonucleotide primers were used in the PCR reaction:

$$
\begin{aligned}
& \text { 22y: } \\
& \text { 5' -CTGCCCTACTTGATTGATGG -3' } \\
& \text { 23y: } \\
& \text { 5' -ATCTTCTCCTCTTCTGTCTC -3' } \\
& \text { 24y: } \\
& \text { 5' -TTCTGGATTGTAGCAGATCA -3' }
\end{aligned}
$$

\section{GSTM1 GENE}

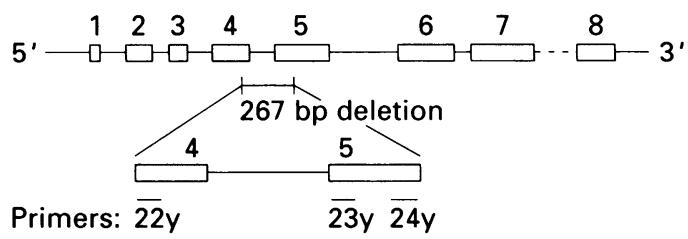

Figure 1 Schematic structure of the GSTM1 gene. The upstream primer (22y) is situated in exon 4, whereas both downstream primers (23y and 24y) are located in exon 5. Both $22 y$ and $23 y$ anneal to GSTM4 in addition to GSTM1 and thus serve as a positive control for the PCR assay. Primer $24 y$ is specific to GSTM1. 

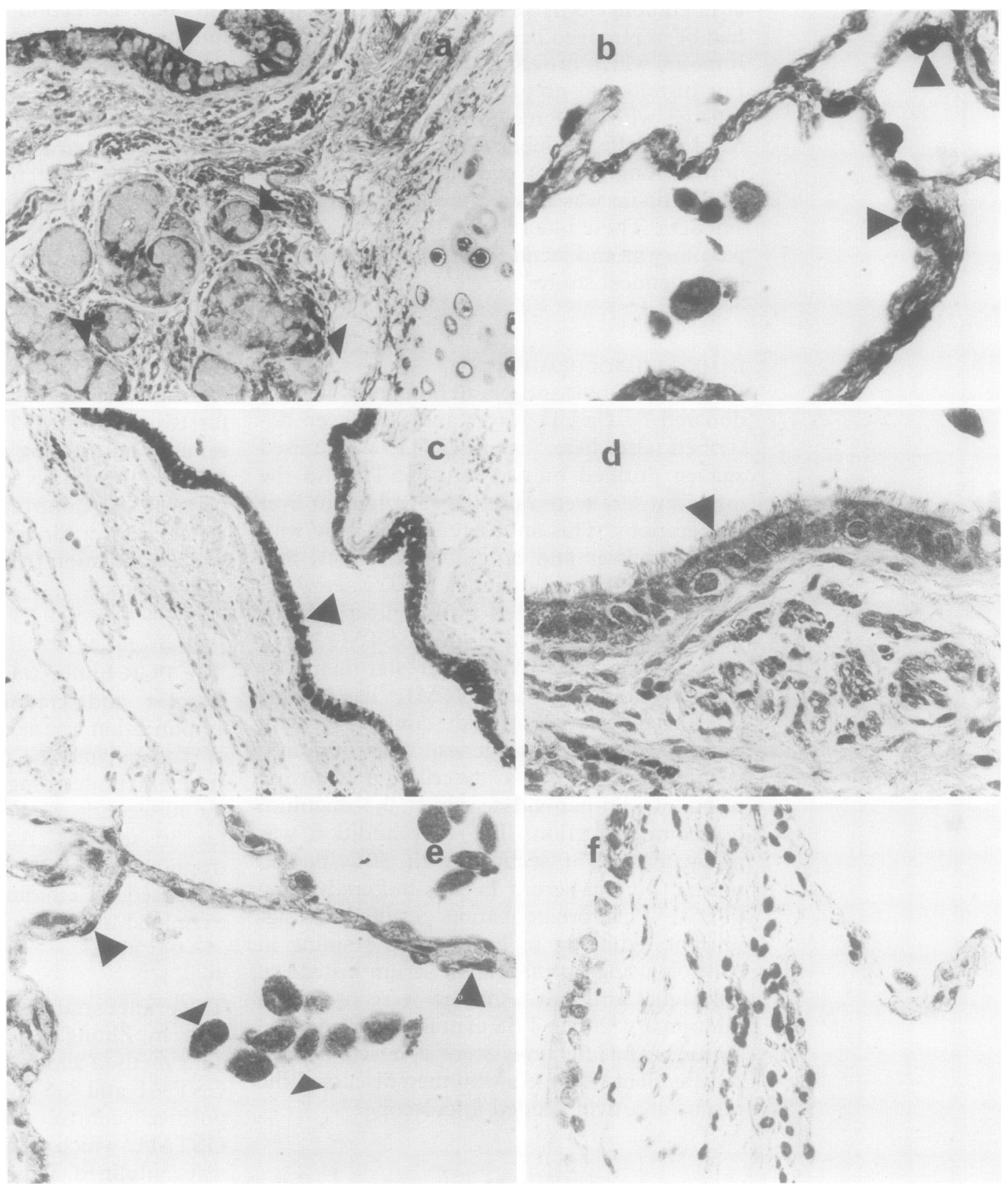

Figure 2 (a) GSTP in bronchial epithelial cells (big arrowhead), serous cells (small arrowhead), and chondrocytes (bottom right side of photomicrograph). (b) Alveolar macrophages in the lumen and lining cells, particularly type II alveolar cells (arrowheads), stained strongly for GSTP. (c) GSTA presence limited to airway epithelium (arrowhead); alveoli and macrophages not stained. (d) GSTM present in bronchial epithelium (arrowhead) including the brush border. (e) Heterogeneous staining of alveolar macrophages for GSTM (small arrowhead) and weak staining of alveoli (big arrowhead) which was more intense than a negative control sample. (f) Negative control showing no significant reaction product. All that is visible is nuclei counterstained with haematoxylin. There is no immunoreactivity.

The primers $22 \mathrm{y}$ and $23 \mathrm{y}$, when used together in a PCR reaction, amplify a DNA fragment of $202 \mathrm{bp}$ in length, while the use of $22 \mathrm{y}$ and $24 \mathrm{y}$ together results in the amplification of a fragment $275 \mathrm{bp}$ long.

\section{Results}

LOCALISATION OF GST ISOENZYMES IN LUNG TISSUE

There was complete agreement between the two observers on the pattern of distribution of GSTs in the lung samples. No formal attempt was made to quantify the amount of GST present, but cases were scored as positive when the staining intensity was greater than a control slide for which non-immune rabbit serum was substituted for primary antiserum (fig $2 f$ ).

\section{GSTP}

GSTP was present in every lung examined. Bronchial epithelial cells were strongly positive with reactivity noted in cytoplasm, brush border, and most nuclei. Muscle, nerve, serous glands, and chondrocytes were also positive (fig 2a). Terminal bronchioles and both type 1 and type 2 pneumocytes contained GSTP. Endothelial cells were not stained. Alveolar macrophages were variably positive (fig $2 b$ ). No differences were noted between smokers and the two tissue samples from non-smokers.

\section{GSTA}

There was GSTA present in the cytoplasm, some nuclei, and brush border of most, but not all, bronchial epithelial cells. Some chondrocytes stained but alveolar lining cells 
and macrophages were consistently negative (fig 2c).

\section{GSTM}

The staining intensity for GSTM was less than for other isoenzymes. Only two cases of the 21 studied showed strong staining for GSTM, seven were weakly stained, and the remainder were negative. The pattern of distribution was the same as for GSTP, however - that is, bronchial epithelium, types 1 and 2 alveolar cells, and macrophages (figs $2 \mathrm{~d}$ and $2 \mathrm{e}$ ).

\section{LOCALISATION OF GST ISOENZYMES IN BRONCHOALVEOLAR LAVAGE FLUID}

All four samples showed reactivity with GSTP antibody, although in two cases GSTP appeared to be partly degraded (fig 3 ). In three cases no evidence was found to indicate that haem was present. In one sample there was trace positivity by testing with Dipstix.

\section{POLYMERASE CHAIN REACTION ANALYSIS}

PCR analysis resulted in specific fragments which were easily interpreted when visualised on agarose gels as described (fig 4). Of 16 DNA samples extracted from archival lung tissue nine were null at the GSTM1 locus. There was no correlation demonstrable between GSTM1 genotype and immunophenotype. Analysis of 350 random DNA

1

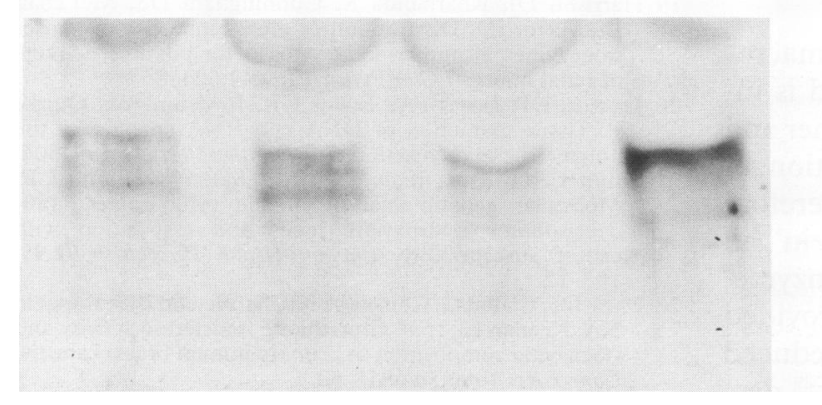

Figure 3 Western blot analysis of bronchoalveolar lavage fluid probed with antibody against GSTP. In lanes 1 and 2 lower molecular weight bands reacting with antibody can be seen, consistent with degradation of protein. This pattern is not seen with the positive control sample of purified GSTP.
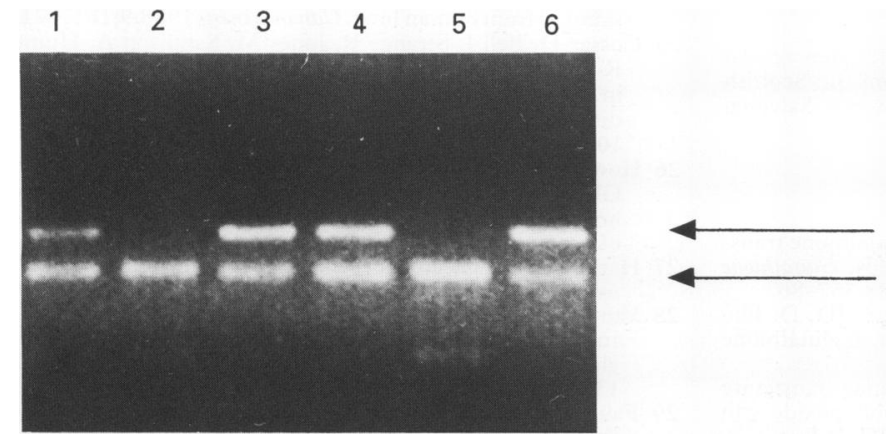

$275 \mathrm{bp}$

$202 \mathrm{bp}$

Figure 4 Examination of DNA amplified by polymerase chain reaction from blood lysates and paraffin embedded tissue clearly identified the null GSTM1 homozygous genotype (lanes 2 and 5) as opposed to the presence of the intact wild type allele (lanes 1 , 3,4 , and 6). In each lane the constant lower molecular weight fragment represents control amplification of GSTM4. samples extracted from blood samples showed that 198 individuals (56\%) were null for GSTM1.

\section{Discussion}

Our findings suggest that GST mediated protection against xenobiotic and oxidative stress in the lung can be divided into two functional compartments. In proximal airways all three cytosolic forms (GST P, A, and M) were present in lining epithelium, whereas the distal alveolar compartment contained GSTP and GSTM but no GSTA in both type 1 and 2 pneumocytes as well as macrophages. This is consistent with biochemical studies which showed that GSTP is the predominant lung isoenzyme. ${ }^{2324}$ In a previous study of GST in human lung development all isoenzymes were identified, with GSTP being the predominant isoenzyme. The levels of GSTP were higher during fetal development, with strong reactivity in bronchi and protoalveoli, and fell during late gestation. ${ }^{25}$ In another study of only three human lungs ${ }^{16}$ GSTP, GSTA, and GSTM were all reportedly present in alveoli. This is inconsistent with the work of Fryer and colleagues in fetal lung ${ }^{17}$ and with our own study. The discrepancy may be because an immunofluorescence assay was used in the study of Awasthi et $a l^{16}$ which is more sensitive but also produces higher backgrounds. When we omitted the preincubation of sections with a blocking buffer containing $50 \%$ human serum we also obtained diffuse alveolar staining with all antibodies. Our findings are in broad agreement with the distribution of GST enzymes reported by Antilla and colleagues. ${ }^{18}$

In previous studies of localisation of GST in mouse and rat lungs ${ }^{415}$ cellular GST was restricted to bronchial epithelial cells, including the brush border, with virtually no GST identifiable in alveoli. In addition, GSTP in rat lung was also identified as an extracellular protein in association with elastin. ${ }^{15}$ This was apparent in electron but not light microscopic preparations. We found no evidence for extracellular, interstitial GST but we have suggested that GSTP is present in bronchoalveolar lavage fluid. Another possibility for the presence of GSTP in bronchoalveolar lavage fluid is by leakage from red blood cells. However, three of the samples were negative for haem when tested and the fourth showed a trace of haem. This may indicate the presence of blood contamination, but another possibility is that haem present in cytochromes P450 was detected. Cytochromes P450 are thought to be a normal constituent of the epithelial lining fluid in the lung ( $\mathrm{R}$ Richards, personal communication). Furthermore, our findings are consistent with a previous study in which both GSTA and GSTP were found in bronchoalveolar lavage fluid of tumour-bearing lungs. ${ }^{26}$

Cigarette smoke contains a plethora of chemicals, many of which are electrophilic or become electrophiles after metabolism principally by cytochrome P450 enzymes. These compounds serve as substrates for GSTP, GSTA, and GSTM. Proximal airways contained GSTA 
which is involved in selenium-independent glutathione peroxidation reactions, and which may detoxify DNA and lipid hydroperoxides. ${ }^{1}$ Its presence in the brush border is therefore suggestive of a role for GSTA in the protection of bronchial epithelium. Most acute damage following cigarette smoke inhalation is seen in small distal airways and alveoli, ${ }^{27}$ a site lacking this selenium-independent peroxidase protection. In individuals null at the GSTM1 locus it therefore follows that the level of protection in distal airways afforded by GSTs is significantly reduced. Several reports have suggested that the expression of GSTM in lung shows evidence of polymorphism which is consistent with the gene expressed being GSTM1 rather than GSTM4. ${ }^{1723}$ In one study of 10 lungs, however, no evidence of polymorphic expression was seen although the level of GSTM catalytic activity was markedly variable between cases. ${ }^{24}$ In this present study we cannot confirm that the immunohistochemical expression seen was specifically the polymorphic enzyme GSTM1 rather than the non-polymorphic GSTM4. Further studies are in progress to address this problem by analysis of $\mathrm{mRNA}$.

Support for the association of GSTM1 status and disease susceptibility comes from in vitro studies of leucocytes which showed that cells from GSTM1 null individuals were more prone to epoxide-induced DNA injury and sister chromatid exchange. ${ }^{28}$ For this reason the determination of GSTM1 genotype is important in considering individual susceptibility to xenobiotics by inhalation of cigarette smoke. This is equally relevant to metabolism occurring in the lung, as well as other organs including the liver where there is high expression of the enzyme. ${ }^{29}$

The presence of GSTP in alveolar macrophages and bronchoalveolar lavage fluid is interesting. GSTP functions as a homodimer and it can be readily inactivated by oxidation of reduced sulphydryl groups. ${ }^{13}$ It may therefore function as a "sacrificial reactive protein" in addition to being a GST-dependent enzyme. Indirect support for this suggestion is provided from a study where cigarette smoke reduced GSTP activity in alveolar macrophages, ${ }^{29}$ despite the fact that cigarette smoke contains many chemicals which might increase GSTP expression. In these cells GSTP activity may have been reduced by oxidative degradation rather than by reduced expression of the protein.

We are grateful to Dr J D Hayes for providing antibodies against GST. This work was supported by a grant from the Scottish Office, Home and Health Department and by the Salvesen Office,
Trust.

1 Ketterer B, Meyer DJ, Clark AG. Soluble glutathione transferase isozymes. In: Sies H, Ketterer B, eds. Glutathion conjugation. London: Academic Press, 1988:357-86.

2 Mannervik B, Awasthi YC, Board PG, Hayes JD, Di Illio $\mathrm{C}$, Ketterer $\mathrm{B}$, et al. Nomenclature for human glutathione C, Ketterer B, et al. Nomenclature for h.m

3 Jernstrom B, Martinez M, Dock L. Glutathione transferase catalysed conjugation of benzo(a)pyrene diol-epoxide with glutathione in rat hepatocytes. In: Hayes JD, Pickett CB Mantle TJ, eds. Glutathione S-transferases and drug resistance. London: Taylor and Francis, 1990:111-20.

4 McLellan LI, Harrison DJ, Hayes JD. Modulation of glutathione S-transferases and glutathione peroxidase by the anticarcinogen butylated hydroxyanisole in murin extrahepatic organs. Carcinogenesis 1992;13:2255-61.
5 Zhong S, Spurr NK, Hayes JD, Wolf CR. Deduced amino acid sequence, gene structure, and chromosomal location at a novel human class mu glutathione S-transferase, GSTM4. Biochem $₹$ 1993;291:41-50.

6 Board PG. Genetic polymorphisms of glutathione S-transferases in man. In: Hayes JD, Pickett CG, Mantle TJ, eds. Glutathione S-transferases and drug resistance. London: Taylor and Francis, 1990:232-41.

7 Hayashi S-I, Watanabe J, Kawajiri K. High susceptibility to lung cancer analysed in terms of combined genotypes of P4501A1 and Mu-class glutathione S-transferase genes. fpn f Cancer Res 1992;83:866-70.

8 Strange RC, Matheroo B, Faulder GC, Jones P, Cotton W, Elder JB, et al. The human glutathione S-transferases: a case control study of the indicence of the GST1 0 phenotype in patients with adenocarcinoma. Carcinogenesis 1991; type in pati

9 Zhong S, Wyllie AH, Barnes D, Wolf CR, Spurr NK. Relationship between the GSTM1 genetic polymorphism and susceptibility to bladder, breast and colon cancer. Carcinogenesis 1993;14:1821-4.

10 Zhong S, Howie AF, Ketterer B, Taylor J, Hayes JD, Beckett $\mathrm{GJ}$, et al. Glutathione S-transferase Mu locus: use of genotyping and phenotyping assays to assess association with lung cancer susceptibility. Carcinogenesis 1991;12: 533-7.

11 Seidegard J, Pero RW, Miller DG, Beattie EJ. A glutathione transferase in human leukocytes as a marker for the sus-

12 Fryer AA, Zhao L, Alldersea J, Boggild MD, Perrett CW, Clayton $\mathrm{RN}$ et al. The glutathione S-transferases: polymerase chain reaction studies on the frequency of the GSTM 10 genotype in patients with pituitary adenomas. Carcinogenesis 1993;14:563-6.

13 Mulder GJ, Tekoppele JM. Glutathione conjugation in vivo, in perfused organs and in isolated cells: pharmacogenetic aspects. In: Sies H, Ketterer B, eds. Glutathione conjugation. London: Academic Press, 1988:357-86.

14 Shimizu T. Enzymes functional in the synthesis of leukotrienes and related compounds. Int $\mathcal{F}$ Biochem 1988;20: 661-6.

15 Coursin DB, Cihla HP, Oberley TD, Oberley LW. Immunolocalisation of antioxidant enzymes and isoenzymes of glutathione $\mathrm{S}$-transferase in normal rat lung. $\mathrm{Am} \mathcal{J}$ Physiol 1992;263:L679-91.

16 Awasthi YC, Singh SV, Ahmad H, Moller PC. Immunocytochemical evidence for the expression of GST1, GST2, and GST3 gene loci for glutathione S-transferase in human. Lung 1987;165:323-32.

17 Fryer AA, Hume R, Strange RC. The development of glutathione $\mathrm{S}$-transferase and glutathione peroxidase activities in human lung. Biochim Biophys Acta 1986;883 448-53.

18 Antilla S, Hirvonen A, Vainio $H$, Husgafvel-Pursiainen $K$, Hayes JD, Ketterer B. Immunohistochemical localization of glutathione S-transferases in human lung. Cancer Res 1993:53:5643-8.

19 Harrison DJ, Kharbanda R, Cunningham DS, McLellan LI, Hayes JD. Distribution of glutathione S-transferases isoenzymes in human kidney: basis for possible markers isoenzymes in human kidney: basis for poss
of renal injury. $\mathcal{f}$ Clin Pathol 1989;42:624-8.

20 Jackson DP, Lewis FA, Taylor GR, Boylston AW, Quirke $P$. Tissue extraction of DNA and RNA analysis by the polymerase chain reaction. $\mathcal{F}$ Clin Pathol 1990;43:499-504

21 Smith CAD, Moss JE, Gough AC, Spurr NK, Wolf CR. Molecular genetic analysis of the cytochrome P450debrisoquine hydroxylase locus and association with cancer susceptibility. Environ Health Perspect 1992;98: 107-12.

22 Shea TC, Claflin G, Comstock KE, Sanderson BJS, Burstein NA, Keenan EJ, et al. Glutathione transferase activity and isoenzyme composition in primary human breast cancers. Cancer Res 1990;50:6848-53.

23 Ketterer B, Harris JM, Talaska G, Meyer DJ, Pemble SE Taylor JB, et al. The human glutathione S-transferase supergene family, its polymorphism, and its effects on susceptibility to lung cancer. Environ Health Perspect 1992; 98:87-94

24 Carmichael J, Forrester LM, Lewis AD, Hayes JD, Hayes PC, Wolf CR. Glutathione S-transferase isoenzymes and glutathione peroxidase activity in normal and tumour glutathione peroxidase activity in normal and tumour

25 Cossar D, Bell J, Strange R, Jones M, Sandison A, Hume $R$. The $a$ and $p$ isoenzymes of glutathione S-transferase in human fetal lung: in utero ontogeny compared with differentiation in lung culture. Biochim Biophys Acta 1990 1037:221-6.

26 Howie AF, Bell D, Hayes PC, Hayes JD, Beckett GJ Glutathione S-transferase isoenzymes in human bronchoalveolar lavage: a possible early marker for the detection of lung cancer. Carcinogenesis 1990;11:295-300.

27 Harley RA. Tobacco. In: Dail DH, Hammer SP, eds. Pulmonary pathology. New York: Spinger Verlag, 1988:637-49.

28 Van Poppel G, de Vogel N, van Balderon PJ, Kok FJ. Increased cytogenetic damage in smokers deficient in Increased cytogenetic damage in smokers deficient in
glutathione S-transferase isozyme M. Carcinogenesis 1992; 13:303-5.

29 Faulder CG, Hirrel PA, Hume R, Strange RC. Studies of the development of basic neutral and acidic isoenzymes
of glutathione $S$-transferase in human liver, adrenal, kidney of glutathione S-transferase in human liver,

30 Petruzelli S, Bernard P, Paoletti P, Rane A, Giuntini C, Pacifici GM. Presence of epoxide hydrolase and glutathione S-transferase in human pulmonary alveola macrophages. Eur $\mathcal{F}$ Clin Pharmacol 1988;34:419-21. 